\title{
Application on Communicative Teaching Method in College Oral English Teaching
}

\author{
Haiyan Feng
}

\author{
Department of Foreign Languages, Liaoning Institute of Science and Engineering, Jinzhou, 121013, \\ China \\ Fenghaiyan06214@163.com
}

\begin{abstract}
Keywords: communicative teaching method; college English; oral teaching; communicative competence
\end{abstract}

\begin{abstract}
The purpose of English teaching is to cultivate students' ability to make practical communication in English. Communicative teaching method advocates students as the center, which considers students are decisive factors of learning, emphasizes students' autonomous learning and interaction between teachers and students. Teaching activities should pay attention to cultivating students' innovation ability and communication skills that use languages in the real environment. Communicative teaching method gives priority to listening and speaking, which is very suitable for English oral teaching. Aiming at the problems exist in the college English oral teaching, combining the characteristics of oral English, analyzes the factors affecting English oral teaching, put forward application methods of communicative teaching method in college English oral teaching, which serves for promoting the college English teaching reform, improving the level of English oral teaching and students' language communicative competence.
\end{abstract}

\section{Introduction}

Spoken English is the language form of oral communication which is widely used by people in English speaking countries. Spoken English is usually spread through sound. "Listening, speaking, reading and writing" are important forms for people to communicate with each other through language, which is an important means for people to understand the world, gain knowledge, develop intelligence, communicate feelings. Linguists divide into language skills linguists from different perspectives. From the perspective of the forms of language, listening and speaking are oral languages, reading and writing are written languages; spoken language is the sound form of written language, written language is the written record of spoken language. From the perspective of the development of human language, spoken language is primary, written language is secondary; spoken and written language have obvious differences in the aspects of the manner and means of expression, as well as vocabulary, syntax, information density and language function. From the perspective of cognitive, listening and reading are discourse understanding and information input abilities, speaking and writing are ideas expression and information output skills. The four skills promote each other in the language learning and communication, the lack of any skill will affect normal communication activities.

All the time, students' accepted English learning in the school is mainly to take an exam, in order to cope with various English exams give priority to written, teachers' teaching are more vocabulary and grammar knowledge, a little amount of students can use English fluently to communicate, "dumb" English becomes the biggest obstacle to learning English. Oral English is a skill, especially in accordance with the current situation, the communication between China and the international is getting closer and closer, learning practical oral knowledge can deal with the practical problems encountered in work, business and abroad, etc. The purpose of college English teaching is to cultivate students' comprehensive application ability, especially the ability of listening and speaking, which promotes students can effectively make the information communication of spoken and written in English. Communicative teaching method is the college English teaching method adapts to the requirements, which has a positive promoting effect for improving the teaching level of oral English and students' oral application abilities. 


\section{Communicative Teaching Method}

Communicative approach thinks that language is a communication tool, learning a language should not only master the form and application rules of language, but also learn to make concrete application. Teaching language should teach students how to use the language to achieve communicative purposes, rather than regarding teaching grammar rules and fragmentary words phrases as the ultimate goal. Therefore, communicative teaching method emphasizes that teaching the knowledge of language function, if students don't master language's communication function, there is no ability to use language to communicate. Communicative teaching method emphasizes that put students in real communication scene as far as possible, and it is up to students to go through communicative activities. According to the principles of communicative teaching method, teachers and students all should pay attention to applying learned language in real classrooms and extracurricular communicative activities, it can be conductive to cultivate language communicative competence that teaching and learning in the communicative situation simulates reality.

The basic principles of communicative method teaching include three aspects: first, all activities are around the communication. All teaching activities carried out by teachers in the classroom must take the communication as the center; second, try to reproduce the communicative process. The communication with people is rich and colorful in real life, used language is richer and more colorful in the communicative process, English teaching should reproduce this kind of communicative process; third, don't always correct. Adopting a more tolerant attitude towards students' language errors, especially grammatical errors. The practice that wrong must be rectified can make students not dare to boldly express because of the fear of making mistakes, which interferes with students' free communication.

The form of oral classroom communicative activities mainly has the following kinds: ask and answer with each other, which can be between teachers and students, also between students and students; free dialogue, which can talk about the weather, news and notifications, etc; table activities, two persons discuss something or ask another person to participate in an activity; look at the picture to speak, watching as well as talking, talking as well as asking questions, explaining each other; telling stories, roles can be divided to tell stories, or each person speaks one piece; group activities, several people are divided into a group to put forward their own opinions according to a certain problem; situational dialogue, according to different situations to talk; role play, according to the requirements of the situation, different roles are played by students; character interview, students play a role of reporter to interview for classmates or social celebrities played by classmates; workshops, collective or group discussion is made for a certain project, each person put forwards opinions or views; debates, students are divided into two sides to make a debate on a controversial subject; news broadcast, collect and select news programs from the radio and television or newspapers and magazines to report; speech contest, determine the theme, speech is made by students, everyone comments.

\section{Characteristics of Spoken English}

"Speaking English" is not only a kind of ability, what is more that a skill, a person's English reading and writing level does not represent oral communicative ability, there are essential differences between oral and written. English spoken language features are embodied in discourse, pragmatics, syntax and vocabulary, etc. Specific description is as follows:

First, discourse features of spoken English. A slip of the tongue and hesitation pause in daily communication often trouble the speaker, which are all normal phenomenon, because speakers do not have enough time to plan what to say. Discourse's significant signs include: hesitation pause, which is normal inconsistent phenomenon in the oral communication; repeat, successful communication can be repeated, repeat attributes to the normal phenomenon; correction, in the process of communication, the speaker stops to correct inappropriate or incorrect statements. Chaos refers to the phenomenon that the beginning of a sentence or clauses is inconsistent with the ending vocabulary; incomplete, the speaker pauses for a moment for failure to continue the conversation. 
Second, pragmatic characteristics of spoken English. Language is the pronunciation symbols system used for human communication, pragmatic is the application used for language by users in a certain context. Pragmatic characteristics of spoken English include: approach and priority, some types of discourse usually come in pairs, for example, greetings and responses, question and answer, invite and accept, etc; fuzzy refers to a speaking skill used for avoiding too much explanation in the daily conversation; emotional expression, parenthesis in the daily conversation, including thanks, please, bye, would you, could you and sorry to express speakers' feelings; dialect, usually indicates speakers' education background and social status.

Third, grammatical characteristics of spoken English. The most obvious characteristic is informal and non-standard. Informal is closely combined with traditional habits, informal refers to draw further apart with traditional habits; non-standard link to the language's influence, which refers to the language type different with standard types. Specific features include: ellipsis, ellipsis of a certain or some words in the complete grammatical structure; word abbreviations, short form of a word; the "number" in the grammar, English has a singular and plural, which should be consistent in the sentence; tense, English has two kinds of tenses and two types of bodies, the present tense and past tense, the progress and complete body. Two kinds of tenses and bodies can be applied to make up different kinds of combinations.

Fourth, vocabulary characteristics of spoken English. In daily informal communication, people often use inaccurate vocabulary, verb phrases or slang to make the discourse more accord with the occasion. Specific characteristics are as follows: commonly used vocabulary, native language speakers prefer to use common words in daily conversation; limited vocabularies, smooth daily communication only need five thousand words in one million vocabularies of English; radiation of significance, although oral vocabulary is limited, does not represent the amount of transferred information are less; abstract, in order to deliver more information in limited time, tend to avoid too specific to express; inaccurate vocabularies, in the daily communication it is not necessary to use every vocabulary accurately, which makes people feel comfortable and relaxed; slang, produced in some special occasions, or some non-standard use for standard vocabulary.

\section{Influence Factors of Oral English Teaching}

There are many factors affect the ability of oral English, which are summarized into three aspects: teaching, teachers and students.

First, teaching. The disadvantage of the traditional English teaching modes is the lack of the necessary context. In the language teaching, the context is the premise of teaching, and the background of learning. In the process that non-active students learn language, complete and real context is not only the foundation of learning a language, but also can promote the non-native language learning; oral practice mode is usually dull in the classroom teaching, which is often simply imitation and retelling, the demand is lower, students' enthusiasm is not high, and the practice time is also limited; classroom practice atmosphere is not natural, students need to face students from the whole class or more classes, who are afraid of making mistakes, easily produce the sense of anxiety and tension.

Second, teachers. The low level of English teachers' oral is an important factor that affect teaching, pronunciation is not accurate, applying English cannot be fluent, which are very unfavorable to cultivate students' oral ability; teachers grasp inaccurately students' English levels, often occurs that requirements are too much high, topics are too large or tasks are too difficult, which makes students produce the emotion of fear or anxiety; some teachers always think students do not understand, after speaking clearly in English, also explain in Chinese, which is not conducive to cultivate students' English thinking ability; some teachers worry about students' oral speed is slow or there is an error, do not give opportunities to students to speak with each other in the classroom, students lack of proper training in the classroom.

Third, students. The object of education is students, students are the study main body, the teaching effect is directly related to students' level and effort. Students' English basis knowledge is not solid, pronunciation and intonation are not accurate, vocabulary is poor, grammar is not 
proficient, independent training is less, which leads to language application ability is not strong, even if it is not skilled on the language knowledge which has been mastered, it's too hard to use. Many students have the emotion that afraid of difficulties, resulting in the formation of mental obstacle. Many students are "dumb English", only pay attention to memorizing words and using grammar knowledge to answer questions, do not pay attention to oral expression, English thinking is not used from the macro level.

\section{Application on Communicative Teaching Method in College Oral English Teaching}

Based on the basic principles of communicative teaching method, in view of the factors influence on spoken English teaching, with reference to previous research results, the application methods of communicative teaching method in college spoken English teaching are as follows:

First, provide a real language environment. Communicative teaching method emphasizes language's authenticity. In the college spoken English teaching method, teachers should filter the language scene really used in students' real life to train. Through language learning, students should not only master the language form and basic rules of applying, but also learn how to use the language in a real context. In the teaching process, teacher should first arouse students' enthusiasm, consider in advance what kind of language materials are closely linked to the real life, the purpose of teaching students to learn English is communication rather than a test. Students are more familiar to their own professional topics, pay more attention on hot issues, students' attention will be focused on using appropriate language to express their views. The new college English teaching materials pay much more attention to cultivating communicative competence, which provide many communicative materials, some sentence patterns provide the context content for the actual communication, teachers should make full use of these contents to create oral communication environment, through the ways that students read conversation in roles or simulate the actual situation to show, which lets students actively participate in classroom interaction.

Second, weakening the grammatical problems in oral expression. Grammar is the common law in the use of human language. Learning grammar well can obtain a systemic knowledge of language, daily communication also can more accurately express, as well as the passport to open advanced usage of English. Therefore, traditional English teaching, from the initial phase which trains the ability of using language conforms to grammatical norms, students' oral expression appears non-standard usage, teachers immediately correct, stress the importance of using standard language. This approach affects the interest and enthusiasm of learning English. Communicative teaching method thinks that students make mistakes is a normal phenomenon, which not only is not a problem, but conducive to learning. The purpose of English learning is not the test, but the application, and makes learning has a correct grammar consciousness, through understanding and application, cultivates sensitivity for English and the ability to judge right and wrong, lets students conclude grammatical phenomenon by themselves in the learning process, and have the ability to autonomously learn grammar in the communication. Communicative teaching method emphasizes that fluency degree of speaking is more important than accuracy. Teachers constantly correct mistakes will disturb students' thinking ways, divert attention. With the continuous improvement of expression ability, students can gradually correct grammar mistakes.

Third, cultivate students' intercultural communicative competence. Intercultural communication is the communication between people of different cultural background, cultural differences impact on intercultural communication, cultural differences reflect in all aspects of culture, including religious beliefs, values, ways of thinking, way of life and relationships. The greater cultural differences are, the greater the possibility of difficulties occur in intercultural communication. Intercultural communicative competence is the intrinsic ability of individual, which be able to handle the key problems in intercultural communication, such as cultural differences, cultural strangeness, the attitude within cultural groups, and the consequent psychological pressure, etc. Intercultural communication competence consists of knowledge factors, emotional factors, situational features and mental activity characteristics. Among them, knowledge factors refer to that communicators should understand the purpose of cultural communication object, context and 
people's requirements on appropriate behavior; emotional factors refer to the attitude that communicators treat communication objects from different cultures and intercultural communicative behavior, cultural differences in intercultural communication context bring potential uncertainty; situational characteristics, including environment, cultural contact and social role; mental activity factors are the embodiment of knowledge and emotional factors, the content includes verbal and nonverbal expression, role playing.

Fourth, cultivate students' English thinking ability. Developing students' intelligence and cultivating thinking ability are an important task of classroom teaching. Language is a tool of thinking, language thinking is the medium that transforms language learning into language communication. Using English thinking is to make use of language to express without the intervention of mother tongue, without the process of "heart translation", fully thinking in English, comprehension and expression in English. In English teaching, teachers should adopt various methods, fully mobilize students' various senses, link up language materials and thought directly. Specific methods include: creating a relaxed classroom atmosphere to provide a good growth space for students' English thinking ability; encouraging students cooperate and interact to make the mind active, creative thinking is usually produced in the collision of mind; carefully designing study cases to inspire innovative thinking potential based on the combination of theory and application; creative thinking cultivation cannot do without imagination, encourage students to elaborate imagination; positive comments on learning activity, which let students experience the joy of success, strengthen the awareness of innovative thinking.

Fifth, actively create interactive language classroom to promote exchanges. Creating an interactive language classroom lets students participate in social practice, which creates a relaxed and natural atmosphere to arouse students' interest. Designing interactive activities should follow the following principles: starting from students' needs, including language form training and information transmission practice that improve fluency degree; apply real language and context; arouse students' intrinsic motivation; provide appropriate feedback and appropriate error correction; fully reflect the natural link of speaking and listening; provide students with the opportunities of active oral communication; encourage students to improve oral expression ability. Based on these principles, a variety of methods can be used in the classroom such as communicative games, role playing, drama, interview, group discussion and double activities. At the same time, in order to make up for the lack of time in class, more rich and colorful extracurricular activities actively are carried out, constructing the second classroom, including the English corner, clubs, salon, party and academic reports, etc, which causes student to gain more experience, actively participate in the opportunities to speak English.

\section{References}

[1] H. R. Su, "The teaching mode of oral English under the guidance of communicative approach," Knowledge Economy, vol. 19, no. 11, pp. 128-129, 2016.

[2] Y. Liu, "On the characteristics of spoken English," Chinese and Foreign Educational Research, vol. 3, no. 11, pp. 47-48, 2010.

[3] Y. M. Wang, "The Application of Communicative Language Teaching in Oral English Teaching for Non-English Majors," Journal of Changchun Normal University (Humanities and Social Sciences), vol. 30, no. 5, pp. 175-178, 2011.

[4] R. Q. Liu, "Deletion and correction strategy in English learners' intercultural communicative competence," Contemporary Education Sciences, vol. 30, no. 18, pp. 58-60, 2015.

[5] L. Wu, "Strategy of College Students' intercultural communication competence," Educational exploration, vol. 34, no. 6, pp. 91-92, 2014.

[6] N. Bo, "Talking about how to improve oral English ability by using communicative approach," Journal of Yanbian Education College, vol. 28, no. 1, pp. 190-197, 2014. 